\title{
Contribution of Bone Scintigraphy in the Diagnosis of a Calcaneus Fatigue Fracture in a Case at the Nuclear Medicine Department of Idrissa Pouye General Hospital (HOGIP) in Dakar
}

\author{
El-Hadji Amadou Lamine Bathily1,2, B. Ndong2,3, 0. Diop²,3, M. S. Djigo',2, K. Gueye2, A. Kokou4, \\ G. Thiaw2, G. Mbayes, L. A. D. Diouf5, M. Soumboundou's, A. R. Djiboune ${ }^{5}$, P. M. Sy5, O. Ndoye², \\ M. Diarra5, M. Mbodj1,2 \\ ${ }^{1}$ Nuclear Medicine Department, General Hospital of Idrissa Pouye (HOGIP), Dakar, Senegal \\ ${ }^{2}$ Biophysical Laboratory, FMPO, Cheikh Anta Diop University (UCAD), Dakar, Senegal \\ ${ }^{3}$ Nuclear Medicine Department, Hospital Dalal Jamm, Dakar, Senegal \\ ${ }^{4}$ Biophysical Laboratory, University of Lome, Lome, Togo \\ ${ }^{5}$ Laboratory of Physical and Pharmaceutical Biophysics, FMPO, Cheikh Anta Diop University, Dakar, Senegal \\ Email: bathilyssd@yahoo.fr, elhadji.bathily@ucad.edu.sn
}

How to cite this paper: Bathily, E.-H.A.L., Ndong, B., Diop, O., Djigo, M.S., Gueye, K., Kokou, A., Thiaw, G., Mbaye, G., Diouf, L.A.D., Soumboundou, M., Djiboune, A.R., Sy, P.M., Ndoye, O., Diarra, M. and Mbodj, M. (2020) Contribution of Bone Scintigraphy in the Diagnosis of a Calcaneus Fatigue Fracture in a Case at the Nuclear Medicine Department of Idrissa Pouye General Hospital (HOGIP) in Dakar. Open Journal of Medical Imaging, 10, 62-71.

https://doi.org/10.4236/ojmi.2020.101006

Received: January 8, 2020

Accepted: March 28, 2020

Published: March 31, 2020

Copyright $\odot 2020$ by author(s) and Scientific Research Publishing Inc. This work is licensed under the Creative Commons Attribution International License (CC BY 4.0).

http://creativecommons.org/licenses/by/4.0/ (c) (i) Open Access

\section{Abstract}

Introduction: Fatigue fractures are secondary to excessive, unusual, repeated mechanical stress, occurring on healthy bone. Bone scintigraphy (BS) with 99mTc-HMDP is an excellent means of diagnosis. We report a case of stress fracture of the calcaneus with scintigraphic diagnosis, in a marathon runner. $\mathrm{Pa}$ tient and Methods: $\mathrm{He}$ is a 40-year-old athlete in overtraining with right calcaneal pain on running, intense at first, moderate in the middle and then persistent after exercise. The interrogation found no trauma to the right foot and the x-ray of the foot was without abnormality. The so 3 phases were performed following an injection of $564 \mathrm{MBq}$ of $99 \mathrm{mTc}-\mathrm{HMDP}$, with a SPECT gamma camera. Results: Bone scintigraphy found in the early phase, hyper-perfusion and hyper-fixation of the right calcaneal region compared to its left counterpart and in the bone phase persistence of focal hyperfixation opposite the right calcaneus. This scintigraphic aspect of the right calcaneus in an overtrained marathon runner, in a painful context and in front of a normal X-ray, made us evoke a fracture of fatigue. A complementary CT scan performed two days after the BS was without abnormality. Conclusion: Fatigue fractures are micro-fractures generally not noticed on radiography and CT. BS due to its high sensitivity is an excellent or the best tool for the early diagnosis of stress fractures. 


\section{Keywords}

Fatigue Fracture, Bone Scintigraphy, Sports

\section{Introduction}

Fatigue fractures or stress fractures are secondary to non-violent, repetitive stresses of moderate amplitude, occurring on previously healthy bone [1]-[7]. They occur in the absence of metabolic disorders and any specific trauma [3] [7] [8] [9]. They were first reported in 1855 by Breithaupt and mainly among military personnel [10]. Devas [11] in 1958 was one of the first authors to study stress fractures in athletes and running is the main cause [10] [12] [13] [14]. The vast majority of fatigue fractures occur at the lower extremities [15] [16] [17]; the calcaneus being the second location after the tibia [3] [4] [18].

These fractures are favored by a period of unusual physical activity, such as overtraining or a change in training [4] [12] [18]. Although radiography is the primary diagnostic modality for detection of skeletal trauma, there are many occasions when radiographs may initially fail to diagnose an injury. Also, there are several types of injuries which are not diagnosable by routine radiographic methods but can be detected easily by nuclear medicine techniques [5] [10] [16] [19]. However, magnetic resonance imaging (MRI) is also likely to provide an early diagnosis of traumatic bone injuries related to sports [5] [7]. There are four primary categories of injury where nuclear medicine techniques may be of use. These include 1) stress fracture and periosteal injury; 2) covert fractures; 3) joint abnormalities and injuries to connective tissues, especially where they attach to bone; and 4) acute skeletal muscle injury and rhabdomyolysis. One of the most important features of the use of nuclear medicine techniques in the evaluation of sports and traumatic injury is the ability, in most cases, to be able to differentiate among these various categories [5] [20].

Bone scintigraphy (BS) at $99 \mathrm{mTc}-\mathrm{HMDP}$, is a good way to highlight the fatigue fracture.

We report a case of stress fracture of the calcaneus for scintigraphic diagnosis, in an athlete.

\section{Patient and Methods}

He is a Senegalese, 40-year-old marathon runner, presenting for two months approximately, right calcaneal pain occurring during the race, intense at the beginning, moderate in the middle and then persistent after the effort. This pain got worse a month ago after participating in a marathon. The interrogation found overtraining linked to the preparation of the marathon, and an absence of trauma to the right foot.

The X-ray of the foot carried out twice is without abnormality. He was then referred to the nuclear medicine department of Idrissa Pouye General Hospital 
(HOGIP) (Dakar, Senegal) at April 14, 2019 for a search for a stress fracture.

The BS was carried out according to the 3-phase protocol, following an injection of $564 \mathrm{MBq}$ of hydroxy methylene Diphosphate labeled with metastable Technetium 99 (99mTc-HMDP), with early dynamic acquisition (vascular and tissue phase) supplemented by a late bone acquisition (whole body scan and centered statics). It was made using a gamma camera SPECT (Single Photonic Emission Computer Tomography) double head, equipped with a low energy and high resolution collimator. The gamma camera was not paired with a CT (Computed Tomography).

\section{Results}

Bone scintigraphy found:

- In the early phase (Vascular or phase 1 and tissue or phase 2): hyper-perfusion (Figure 2) and hyper-fixation (Figure 1) of the right calcaneal region compared to its left counterpart more visible on the posterior acquisition. Indeed, the comparative study of perfusion curves shows a curve of the right foot always above that of the left foot (Figure 2). In addition, the right/left or Examinated (E)/Reference $(\mathrm{R})$ perfusion reports find values ranging from 1.30 to 3.01 , reflecting the hyper-perfusion on the right (Figure 3 ).

- In the late or bone phase (phase 3 ) we noted on the whole body scintigraphy (Figure 4) as well as on the static images (Figure 5), a persistence of focal hyperfixation projecting opposite the right calcaneus. It was visible on the anterior side but more prominently on the posterior side.

- This scintigraphic aspect of the right calcaneus in an overtrained marathon runner, in a painful context and in front of a normal radiography, had made us evoke a fracture of fatigue.

Like the X-ray, the complementary CT scan of the feet performed two days after the BS was normal (Figure 6).

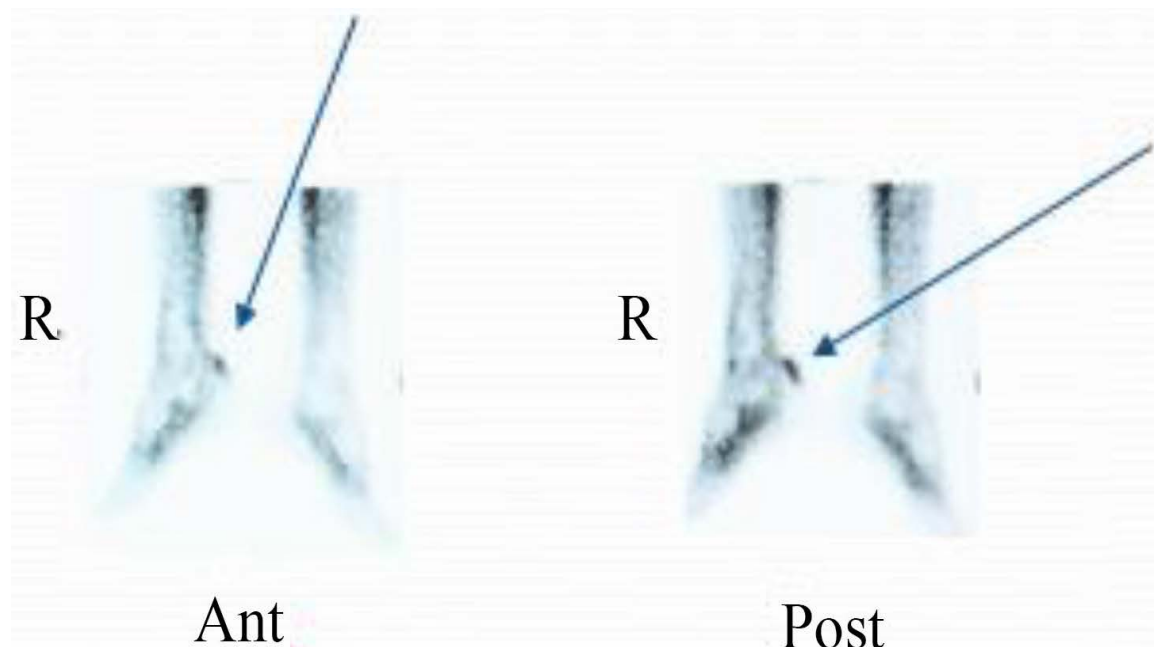

Figure 1. Bone scintigraphy (early phase): side hyperfixation of the right calcaneal region. 


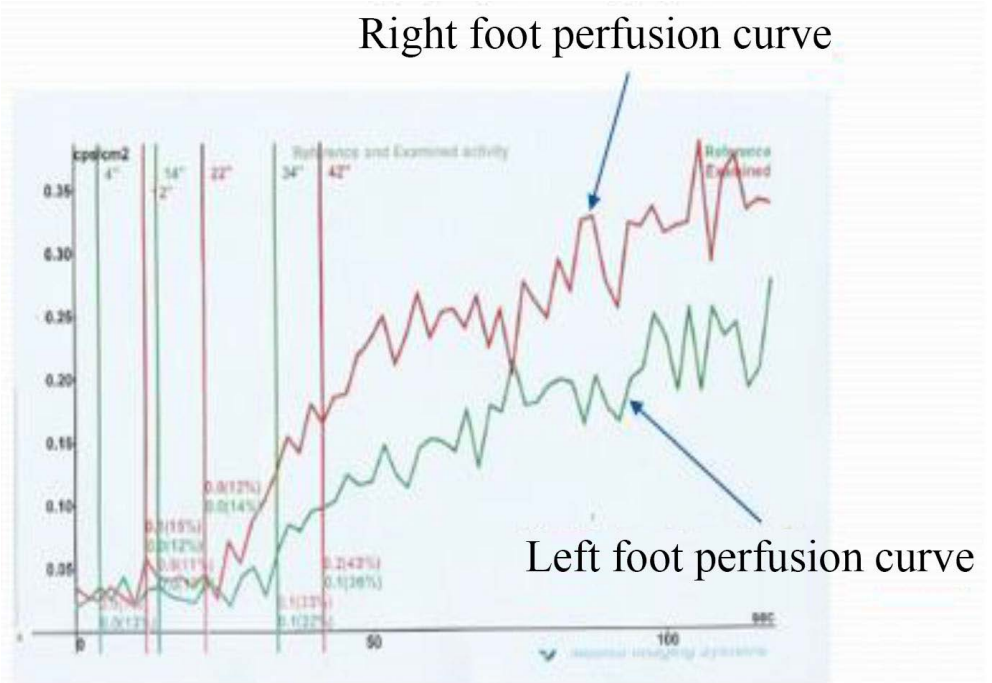

Figure 2. Infusion curve of both feet (right hyperfixation).

\begin{tabular}{|l|l|}
\hline E/R ratio $(10 \mathrm{sec})$ & 1.40 \\
\hline E/R ratio $(30 \mathrm{sec})$ & 3.01 \\
\hline E/R ratio (Phase 1) & 1.33 \\
\hline E/R ratio (Phase 2) & 1.30 \\
\hline
\end{tabular}

Figure 3. Right foot (E)/left foot (R) Infusion reports.

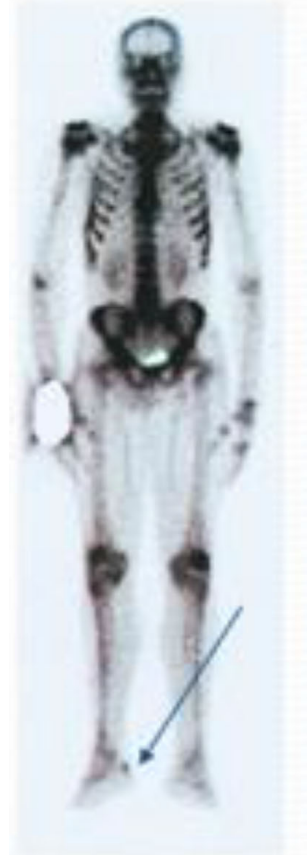

Ant

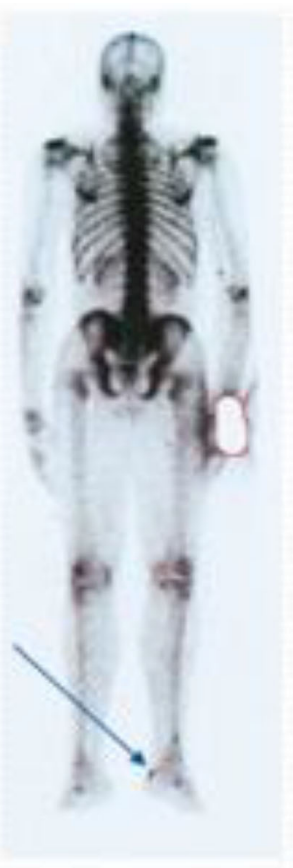

Post

Figure 4. Whole Body Scan: hyperfixation at the right calcaneus. 


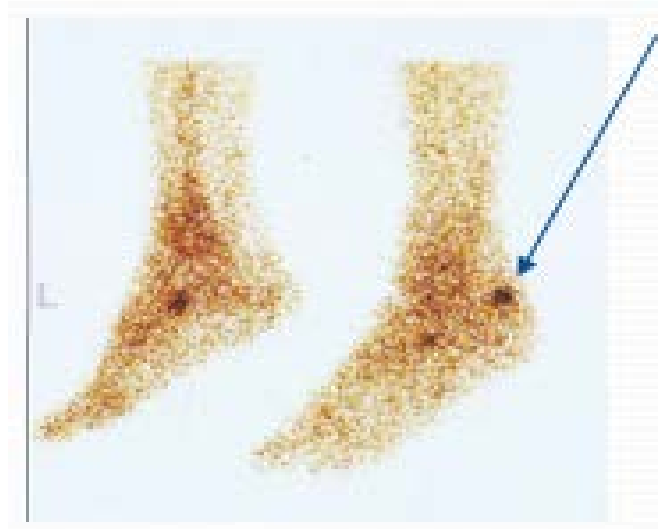

Figure 5. Late static acquisition: hyperfixation at the right calcaneus.

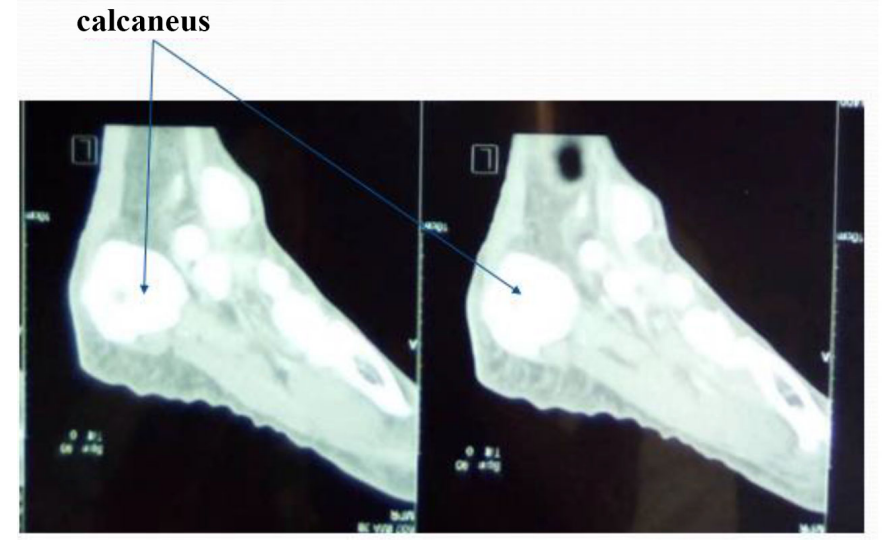

Figure 6. Normal right foot CT (no fracture).

\section{Discussion}

The field and the context of occurrence of the fatigue fracture in our case are widely found in the literature. He is indeed a marathon athlete in overtraining. Michael T. Reeder et al. [10], Brent W. S. [21] stated that running is the cause in the vast majority of stress fractures. It is the same as Prather et al. [22]. Matin P. [5] reported that these lesions are frequently observed in runners and other athletes whose training regimen produces unusually heavy stresses on bone cells. Indeed stress fractures occur when the stresses applied to the bone cause changes in the bone greater than the body's ability to neutralize them. The resulting lesion is probably due to much greater bone resorption than bone replacement [5] [21]. Paycha [7] argued that the classic trigger is a recent and ill-suited change in training conditions. They are also commonly found in army recruits and other untrained people who participate in new types of training. In addition, people with biomechanical abnormalities such as walking or running may be prone to this type of injury [5].

Michael T. Reeder et al., Brent W. S. [10] [21] stated that running is the reported cause in the vast majority of stress fractures. Stress fractures have been attributed to many factors, including: the training surface [23]; training tech- 
niques [24]; inappropriate footwear [23]; biomechanical anomalies [13] [25] and poor conditioning [23] [26]. Gérson L. K. [27] also described a tibial fatigue fracture in a marathon runner.

The bone structure, although subject to efforts within the limits of its capacities, undergoes elastic deformation and regains its histological configuration at the end of the stress. However, when these stresses exceed its normal resistance, the elastic deformation is replaced by plastic deformation; in other words, there is no return to the previous situation, bone reabsorption thus prevailing if the conditions remain, and microfractures occur. In this stage of the evolution of the stress fracture, physiological alteration occurs without apparent anatomical implication [27]. The pursuit of "sports" requirements, after the initial installation of the microfracture, results in an open fracture, this time associated with anatomical modifications of the bone structure. Thus, we can say that the establishment of the fatigue fracture begins with a physiological modification; when the cause of this alteration remains, the situation ends in an anatomical modification [27]. In fact, following intense, unusual, repeated mechanical stresses, an accentuation of osteoclastic resorption takes place with an increase in bone turnover, which is only followed belatedly by an increase in osteoblastic formation. This temporary embrittlement exposes to fracture decompensation in the event of continued overuse [7] [11] [21] [28].

We know that X-rays are of little use in detecting acute stress fractures; therefore, the diagnosis of these abnormalities has become mainly dependent on nuclear medicine techniques. The clinical picture of our patient is also widely reported in the literature. Paycha [7] and Mouaden A. [9] reported that the reason for the consultation was a sudden onset pain without trauma, typically mechanical, worsening with exertion and calmed by rest. The diagnosis of fatigue fracture is evoked in athletes in the face of progressively disabling mechanical pain, contrasting with the poor physical examination.

The scintigraphic aspect of hyperfixation at the early and late phase of the right calcaneus in a overtrained marathon runner, in a painful context and in front of a normal radiography, made us evoke a fatigue fracture. This scintigraphic aspect is classic and very widely described [3] [4] [7] [9] [17] [18] [27] [29]. In fact, the 4 pillars of the diagnosis are: the history of the athlete, isolated exertion pain, normal radiographs and positive bone scan [7]. The radiographic signs are most often delayed ( 2 weeks to 3 months), discreet, sometimes even absent (tarsus, metatarsals). The same late nature of the anomalies visible on the computed tomography (CT) should be emphasized [7] [9] [12] [15] [17] [21] [27].

All the authors thus agree on a sensitivity of bone scintigraphy practically equal to $100 \%$ [4] [7] [17] [25] [27] [30] [31]. This ideal sensitivity value is only valid for fatigue fractures occurring on healthy non-osteoporotic bone, when a minimum period of 12 hours separates the onset of pain from bone scintigraphy.

The specificity of the dynamic and morphological criteria for the fatigue frac- 
ture is greater than $80 \%$. Among the bone lesions that may resemble the fatigue fracture, the most frequently encountered are osteonecrosis for the metatarsals and the talus, algodystrophy parcel or osteonecrosis for the tibial plateau, osteoid osteoma for the calcaneus and metatarsals. This list is obviously not exhaustive [7] [31].

To achieve an early diagnosis, bone scintigraphy is widely used in this indication, especially in developed countries. Some sports medicine teams even use scintigraphy as the first intention, radiography downshifting into second position and often in a delayed manner.

However, magnetic resonance imaging (MRI) is also likely to provide an early diagnosis of traumatic bone injuries related to sports [32] [33]. The merits of this technique are to identify extra-osseous traumatic injuries and to provide an anatomical image of the lesions. The disadvantages are the limited nature of the exploration, the non-specificity of spinal edema when the fracture line is invisible, a slightly lower sensitivity to scintigraphy when the MRI is not guided by the latter.

The location of fatigue fractures depends on the type of physical activity.

They predominate clearly in the lower limbs and are most often unilateral [4] [9] [10] [17] [25] [34]; the calcaneus being the second location after that of the tibia [4] [18] [35]. The calcaneal localization is benign with a generally favorable evolution [6] [7]. The treatment consists of rest with reduction of the load when pressing on the foot in question.

Conservative therapy for stress fractures involves the use of ice, non-steroidal anti-inflammatory drugs, and rest of the affected bone for several weeks or until pain-free. Additionally, pre-exercise warm-up and stretching, and a gradual return to the offending exercise intensity are indicated. Substitution of a non-weight-bearing exercise, such as swimming (or upper extremity bicycle for lower extremity fractures), may speed recovery without loss of cardiovascular conditioning. Metatarsal and navicular fractures may require short leg casting for six to eight weeks unless comminuted or displaced. In elite athletes, it is more common to perform intramedullary nailing if a joint is not involved [21].

For the prevention, a gradual increase in the intensity of exercise, not to exceed an increase of 10 percent per week, generally is recommended for prevention of all stress fractures. Adequate stretching with warm-up before exercise is advised. The use of lightweight footwear in good condition and smooth, level running surfaces are specifically recommended to prevent lower extremity stress fractures as well as correcting predisposing biomechanical conditions by using custom orthotics or arch supports. A Cochrane Review involving four trials suggested that the use of shock-absorbing insoles may prevent stress fractures and stress reactions of the lower extremities. Another study found that decreased exercise intensity after an initial intense period may be effective in preventing stress fractures but may not be significant when corrected for cluster randomization [21]. 


\section{Conclusion}

Fatigue fractures are micro-fractures generally not noticed on radiography and CT. So due to its high sensitivity is an excellent tool for the early diagnosis of stress fractures. However, a SPECT scintigraphy coupled with tracking CT is essential to increase the specificity of the examination. Although MRI is currently accepted for evaluation of stress injuries of the bone, some limitations and pitfalls remain. Three-phase bone scintigraphy is the gold standard to provide prompt and sensitive diagnosis of stress fractures. Additional SPECT/CT imaging will enhance the diagnostic accuracy of planar bone scintigraphy.

\section{Conflicts of Interest}

The authors declare no conflicts of interest regarding the publication of this paper.

\section{References}

[1] Aaron, A.D. (1994) The Management of Cancer Metastatic to Bone. JAMA, 272, 1206-1209. https://doi.org/10.1001/jama.1994.03520150074040

[2] Abu-Judeh, H.H., Naddaf, S.Y., El-Zeftawy, H.A. and Abdel-Daye, H.M. (1998) G-CSF Induced Bone Marrow Hyperplasia: Characteristic Appearance on Total Body Blood Pool and Delayed Tc-99m MDP Bone Scan. Clinical Nuclear Medicine, 23, 39-41. https://doi.org/10.1097/00003072-199801000-00013

[3] Berehou, F., Haddam, A. and Ben Rais, N. (2009) Apport de la scintigraphie osseuse dans les fractures de contrainte à propos de 5 cas. Médecine Nucléaire, 33, 240-278. https://doi.org/10.1016/j.mednuc.2009.03.004

[4] Granier, P. (2011) Fractures de fatigue, MN-net: Imagerie en médecine nucléaire.

[5] Matin, P. (1987) The Bone Scan in Traumatic and Sports Injuries. In: Fogelman, I., Ed., Bone Scanning in Clinical Practice, Springer-Verlag, Berlin Heidelberg, 121-132. https://doi.org/10.1007/978-1-4471-1407-9_10

[6] McBryde, A.M. (1985) Stress Fractures in Runners. Clinics in Sports Medicine, 4, 737-752.

[7] Paycha, F. and Richard, B. (2001) Exploration scintigraphique du squelette. EncyclMédChir (Editions Scientifiques et Médicales Elsevier SAS, Paris, tous droits réservés), Radiodiagnostic-Squelette normal, 30-480-A-10, 37 p.

[8] Daffner, R.H. and Pavlov, H. (1992) Stress Fractures: Current Concepts. American Journal of Roentgenology, 159, 245-252. https://doi.org/10.2214/ajr.159.2.1632335

[9] Mouaden, A. and Guerrouj, H. (2010) Fracture de stress des membres inférieurs: À propos de cinq observations A039. Médecine Nucléaire, 34, 249-286. https://doi.org/10.1016/j.mednuc.2010.07.008

[10] Reeder, M.T., Dick, B.H., Atkins, J.K., Pribis, A.B. and Martinez, J.M. (1996) Stress Fractures Current Concepts of Diagnosis and Treatment. Sports Medicine, 22, 198-212. https://doi.org/10.2165/00007256-199622030-00006

[11] Devas, M.B. (1967) Shin Splints, or Stress Fractures of the Metacarpal Bone in Horses, and Shin Soreness, or Stress Fractures of the Tibia, in Man. The Journal of Bone and Joint Surgery. British Volume, 49, 310-313. https://doi.org/10.1302/0301-620X.49B2.310

[12] Patric, B. and Frédéric, M. (2019) Catégorie: Traumatologie Dossier (s): Fractures 
Dernière révision.

[13] Sullivan, D., Warren, R.F., Pavlov, H., et al. (1984) Stress Fractures in 51 Runners. Clinical Orthopaedics and Related Research, 187, 188-192. https://doi.org/10.1097/00003086-198407000-00028

[14] Uhmans, H. and Pavlov, H. (1994) Stress Fractures of the Lower Extremity. Seminars in Roentgenology, 29, 176-193. https://doi.org/10.1016/S0037-198X(05)80063-X

[15] Sharma, A.R. (2010) Nuclear Medicine in Sports. Indian Journal of Nuclear Medicine, 25, 129-130. https://doi.org/10.4103/0972-3919.63588

[16] Brill, D.R. (1983) Sports Nuclear Medicine. Bone Imaging for Lower Extremity Pain in Athletes. Clinical Nuclear Medicine, 8, 101-106. https://doi.org/10.1097/00003072-198303000-00002

[17] Sriprapaporn, J. (2012) The Scintigraphic Diagnosis of Stress Fractures in the Lower Extremity. The Thai Journal of Orthopaedic Surgery, 36, 22-28.

[18] Zwas, S.T., Elkanovitch, R. and Frank, G. (1987) Interpretation and Classification of Bone Scintigraphic Findings in Stress Fractures. Journal of Nuclear Medicine, 28, 452-457.

[19] Martire, J.R. (1987) The Role of Nuclear Medicine Bone Scans in Evaluating Pain in Athletic Injuries. Clinics in Sports Medicine, 6, 713-737.

[20] Nagle, C.E. (1986) Cost-Appropriateness of Whole Body vs. Limited Bone Imaging for Suspected Focal Sports Injuries. Clinical Nuclear Medicine, 11, 469-473. https://doi.org/10.1097/00003072-198607000-00001

[21] Sanderlin, B.W. (2003) Common Stress Fractures. American Family Physician, 68, 1527-1532.

[22] Prather, J.L., Nusynowitz, M.L., Snowdy, H.A., Hughes, A.D., McCartney, W.H. and Bagg, R.J. (1997) Scintigraphic Findings in Stress Fractures. The Journal of Bone and Joint Surgery. American Volume, 79, 869-874. https://doi.org/10.2106/00004623-197759070-00006

[23] Greaney, R.B., Gerber, F.H., Laughlin, F.H., Kmet, J.P., Metz, C.D., Kilcheski, T.S., et al. (1983) Distribution and Natural History of Stress Fractures in US Marine Recruits. Radiology, 146, 339-346. https://doi.org/10.1148/radiology.146.2.6217486

[24] Frederichson, M., Bergman, A.G., Hoffman, K.L., et al. (1995) Tibial Stress Reaction in Runners: Correlation of Clinical Symptoms and Scintography with a New MRI Grading System. The American Journal of Sports Medicine, 23, 472-481. https://doi.org/10.1177/036354659502300418

[25] Matheson, G.O., Clement, D.B., McKenzie, D.C., Taunton, J.E., Lloyd-Smith, D.R. and MacIntyre, J.G. (1987) Stress Fractures in Athletes. A Study of 320 Cases. The American Journal of Sports Medicine, 15, 46-58. https://doi.org/10.1177/036354658701500107

[26] Stanitski, C.L., McMaster, J.H. and Scranton, P.E. (1978) On the Nature of Stress Fractures. The American Journal of Sports Medicine, 6, 391-396. https://doi.org/10.1177/036354657800600615

[27] Kempfer, G.L., Figueiredo, A.B., et al. (2004) Stress Fracture and Nuclear Medicine. The Revista Brasileira de Medicina do Esporte, 10, 532-534. https://doi.org/10.1590/S1517-86922004000600010

[28] Jones, B.H., Harris, J.M., Vinh, T.N. and Rubin, C. (1989) Exercise-Induced Stress Fractures and Stress Reactions of Bone: Epidemiology, Etiology, and Classification. Exercise and Sport Sciences Reviews, 17, 379-422. 
https://doi.org/10.1249/00003677-198900170-00014

[29] Sutter, B. and Cazenave, A. (2003) Qu'attend le chirurgien orthopédiste de la scintigraphie osseuse? Médecine Nucléaire-Imagerie fonctionnelle et métabolique, 27, 585-595.

[30] Hulkko, A. and Orava, S. (1987) Stress Fractures in Athletes. International Journal of Sports Medicine, 8, 221-226. https://doi.org/10.1055/s-2008-1025659

[31] Ryan, P.J. and Fogelman, I. (1994) The Role of Nuclear Medicine in Orthopaedics. Nuclear Medicine Communications, 15, 341-360. https://doi.org/10.1097/00006231-199405000-00006

[32] Giammarile, F., Masciocchi, C., Barile, A., Di Pietro, M., Carducci, A. and Baschieri, I. (1994) Three-Phase Radionuclide Bone Imaging and Magnetic Resonance Imaging Detection of Occult Knee Fractures in Athletes. European Journal of Nuclear Medicine, 21, 493-496. https://doi.org/10.1007/BF00173034

[33] Rochcongar, P., Moretti, J.L. and Sabourin, F. (1994) Les explorations des douleurs de jambe. Journal of Nuclear Medicine, 18, 503-510.

[34] Bennell, K.L. and Brukner, P.D. (1997) Epidemiology and Site Specificity of Stress Fractures. Clinics in Sports Medicine, 16, 179-196. https://doi.org/10.1016/S0278-5919(05)70016-8

[35] Fredericson, M., Jennings, F., Beaulieu, C. and Matheson, G.O. (2006) Stress Fractures in Athletes. Topics in Magnetic Resonance Imaging, 17, 309-325.

https://doi.org/10.1097/RMR.0b013e3180421c8c 